\title{
Is International Tourism Growth Supported by Increased Tourism Receipts?
}

\author{
Helena Nemec Rudež \\ University of Primorska, Faculty of Tourism Studies - Turistica, Slovenia \\ helena.nemec@fts.upr.si
}

Tourism demand growth during the period between 2000 and 2016 in 25 European countries is calculated using different tourism indicators. It is shown that the number of tourist arrivals and aggregate tourism receipts increase during the period. Tourism receipts per arrival at current prices show a slight increase in the majority of selected countries, while tourism receipts per arrival at constant prices more or less stagnate, ranging from $-2 \%$ to $+2 \%$, and even exhibit sharper decrease in some countries of Southern and Eastern Europe. It can be concluded that tourism growth is predominantly fueled by the increasing number of tourist arrivals and not by receipts per tourist arrival.

Keywords: international tourism, demand growth, European countries

(cc)BY-SA https://doi.org/10.26493/2335-4194.13.153-156

\section{Introduction}

There are plenty of data reports highlighting the remarkable growth of tourism demand worldwide and discussing the challenges and issues related to tourism expansion. Since there is plenty of literature in the field of tourism demand (for instance, Dogru et al., 2017; Peng et al., 2014; Song et al., 2012) and the tourism industry is one of the most important industries nowadays, generating an important share of GDP and export in many countries, the concept of tourism demand growth should be understood properly. There are various indicators used to measure it in the literature (for instance, Crouch, 1994; Lim, 1997; Li et al., 2005; Song et al., 2010), finding that the number of tourist arrivals is the most-used indicator of tourism demand in academic papers, followed by tourism receipts; on the other hand, the average length of stay and the number of overnight stays are rarely used. Indeed, from the suppliers' viewpoint, the number of tourist arrivals is relevant for transport suppliers and tourist attractions, while the number of overnight stays is obviously more relevant for accommodation facilities. As tourism receipts are important for the country's economy, tourist receipts per arrival give additional information on tourists' spending during their stay and price level.

Sheldon (1993 in Song et al., 2010) and GarciaFerrer and Queralt (1997 in Song et al., 2010) highlighted the difference between the growth in international tourist arrivals and the growth in international tourism receipts. Looking at quantitative tourism indicators (World Tourism Organization, 2018), fluctuations in their values are expressed in short-term periods, while steady long-term growth is observed. The increase in physical indicators (number of arrivals and overnight stays) that is higher than the increase in tourism receipts in the long-run period underlies orientation of tourism demand towards low cost products (such as budget accommodations and low-cost travel) along with the boost of sharing economy providers, promotion sales and sharp competition causing the prices to drop.

There arises a question why tourism demand is increasing - is the reason only in the higher number of 
tourist arrivals or do tourists really spend more? In times when academics, managers and tourism planners are discussing tourism growth at length, the paper attempts to assess the quantitative changes in tourism growth in 25 selected countries across Europe which still has the highest share of international tourists in the world.

\section{Methodology and Data Sources}

The research deals with 25 selected European countries during the 17-year period between 2000 and 2016 in order to research average annual growth rates of tourism indicators. For this reason the following annual data for the 25 European countries were gathered separately: (a) the number of international arrivals, (b) international tourism receipts for travel items (in USD, current prices) (see http://dataworldbank.org) and, (c) GDP deflator $(2010=100)$ for USD (see http://www .imf.org), in order to get changes in tourism export at constant prices. Based on these data, the following indicators were used for further analysis for each country:

- The number of international arrivals;

- Tourism export (at current prices) ${ }^{1}$ represented by international tourism receipts for travel items (in USD, current prices);

- Tourism export per international arrival (at current prices) which is calculated by dividing tourism export (in USD, current prices) by the number of international arrivals;

- Tourism export per international arrival (at constant prices) which is calculated by dividing tourism export (in USD, constant prices) ${ }^{2}$ by the number of international arrivals.

Sixteen annual growth rate coefficients $\left(r_{i}\right.$; where $i$ stands for $2,3, \ldots, 17)$ were calculated for each of the four indicators for each country as follows:

${ }^{1}$ Data for international arrivals for Denmark between 2000 and 2004 are adapted using average annual growth rate between 2005 and 2016.

${ }^{2}$ Tourism export at constant prices in USD (TEreal) is calculated using tourism export at current prices in USD (TEnominal) and USD GDP deflator $(2010=100)$ as follows: $\mathrm{TE}_{\text {real }}=\mathrm{TE}_{\text {nominal }} /(\mathrm{USD}$ GDP deflator/100).

$$
r_{i}=\frac{\text { value in year } n}{\text { value in year } n-1},
$$

where $n$ represents $2,3, \ldots, 17$.

Based on sixteen annual growth rate coefficients $\left(r_{i}\right)$, the average annual growth rate coefficient $(r)$ was compounded for each of the four indicators for 25 countries separately. The following equation was used:

$$
r=\sqrt[16]{r_{2} \times r_{3} \times \cdots \times r_{17}}
$$

\section{Findings}

Looking at Table 1, the number of international tourist arrivals has increased the most in Iceland (11.8\%) during the period between 2000 and 2016 whereas in Poland it has remained more or less at the same level. Thus, average annual growth rate was positive in all 25 countries. Besides Poland, very low average annual growth rate in the number of tourist arrivals is found in mature destinations, like France (0.4\%) and Belgium (0.9\%). Higher growth rate, around $1 \%$ on average, is detected in Western countries, like Denmark (1.1\%) and Italy (1.5\%). In contrast, average annual growth rate of international tourist arrivals is higher in Turkey (7.5\%) and in some Eastern European countries that represent emerging markets, like Estonia (6.1\%), Latvia (8.2\%) and Slovenia (6.6\%). Since these are countries with lower purchasing power along with lower price levels compared to the Western European countries, we can assume that price competitiveness of Turkey and Eastern European countries might have played a vital role in attracting tourists.

Receipts of foreign tourists are measured by tourism export. The average annual growth rates of tourism export by selected country are shown in Table 1 . The lowest growth rate of tourism receipts is found in a mature destination - France (1.6\%). The highest ones were found in Iceland (15.9\%) and two Eastern European countries. In addition, compared to the growth rate of international tourist arrivals, international tourism receipts have grown faster in the majority of countries researched (with the exception of Slovenia, Hungary, Greece and Turkey).

Besides aggregate measures, the tourism demand per arrival gives better information about an average tourist's consumption behaviour. International 
Table 1 Average Annual Growth Rate Coefficients of International Tourist Arrivals, Tourism Export at Current Prices, Tourism Export per Arrival at Current and Constant Prices in Selected European Countries during the Period between 2000-2016

\begin{tabular}{lrrrr}
\hline Country & $(1)$ & $(2)$ & $(3)$ & $(4)$ \\
\hline Austria & 1.0283 & 1.0424 & 1.0137 & 0.9945 \\
Belgium & 1.0092 & 1.0360 & 1.0265 & 1.0071 \\
Czech Republic & 1.0427 & 1.0481 & 1.0052 & 0.9862 \\
Denmark & 1.0107 & 1.0416 & 1.0305 & 1.0111 \\
Estonia & 1.0610 & 1.0697 & 1.0081 & 0.9891 \\
Finland & 1.0219 & 1.0420 & 1.0197 & 1.0004 \\
France & 1.0042 & 1.0164 & 1.0122 & 0.9930 \\
Germany & 1.0400 & 1.0447 & 1.0045 & 0.9855 \\
Greece & 1.0407 & 1.0297 & 0.9894 & 0.9707 \\
Hungary & 1.0364 & 1.0265 & 0.9905 & 0.9717 \\
Iceland & 1.1175 & 1.1591 & 1.0373 & 1.0177 \\
Ireland & 1.0265 & 1.0439 & 1.0169 & 0.9977 \\
Italy & 1.0151 & 1.0243 & 1.0090 & 0.9900 \\
Latvia & 1.0819 & 1.1254 & 1.0402 & 1.0206 \\
Luxembourg & 1.0134 & 1.0564 & 1.0425 & 1.0228 \\
Netherlands & 1.0291 & 1.0427 & 1.0132 & 0.9941 \\
Norway & 1.0416 & 1.0602 & 1.0178 & 0.9986 \\
Poland & 1.0003 & 1.0421 & 1.0418 & 1.0221 \\
Portugal & 1.0444 & 1.0636 & 1.0183 & 0.9991 \\
Slovakia & 1.0418 & 1.1225 & 1.0775 & 1.0571 \\
Slovenia & 1.0660 & 1.0596 & 0.9940 & 0.9752 \\
Spain & 1.0307 & 1.0454 & 1.0142 & 0.9950 \\
Sweden & 1.0364 & 1.0735 & 1.0358 & 1.0162 \\
Turkey & 1.0746 & 1.0577 & 0.9843 & 0.9657 \\
\hline K & 1.0275 & 1.0411 & 1.0132 & 0.9941 \\
\hline
\end{tabular}

Notes Column headings are as follows: (1) average annual growth rate coefficient of international tourist arrivals, (2) average annual growth rate coefficient of tourism export (current prices), (3) average annual growth rate coefficient of tourism export per international arrival (current prices), (4) average annual growth rate coefficient of tourism export per international arrival (constant prices $2010=100$ ).

tourism receipts per arrival (at current prices) perform a positive but modest average annual growth rate in 21 out of 25 countries during the period between 2000 and 2016. The highest one is perceived in Slovakia with an average annual increase of $7.8 \%$, followed by Luxemburg, Poland and Latvia with an increase between $4.0 \%$ and $4.3 \%$. In Slovenia, Turkey, Greece and Hungary average annual growth rate of international tourism receipts per arrival is less than 1 , confirming that receipts per arrival have been decreasing in four out of 25 countries during this period.

By removing the impact of price changes, international tourism receipts per arrival at constant prices reveal real changes in tourism receipts per arrival over time. It has ranged between $2 \%$ to $+2 \%$ in the majority of 25 countries. Further, Greece, Hungary and Slovenia were confronted with a negative average annual growth rate of international tourism receipts per arrival at constant prices between $-2 \%$ and $-3 \%$, whereas Luxemburg, Latvia and Poland have reached the one between $+2 \%$ and $+2.3 \%$. The strongest negative growth rate in receipts per tourist arrival in real terms was found in Turkey (below 3\%) and the highest positive one in Slovakia (above $5 \%$ ).

\section{Concluding Remarks}

International tourism growth is fueled by the increasing number of foreign tourist arrivals as well as by international tourism receipts, but tourism receipts per arrival more or less stagnate. However, there are differences between countries. The highest difference between the average annual growth rate of the number of tourist arrivals and the average annual growth rate of tourism receipts at constant prices is found in Turkey, followed by Iceland and Slovenia. On the other hand, Poland, Slovakia and Luxemburg have had an even slightly higher average annual rate of tourism receipts at constant prices than that of tourist arrivals; both average annual growth rates are also practically equal in Denmark.

It can be derived from this that some countries have not succeeded in attracting tourists who spend more money during their stay, probably due to the increased level of competition. In other words, the increased number of international tourist arrivals related to mass tourism is not reflected in substantive additional receipts per tourist. It can be explained in two ways. Firstly, low-cost business models (such as 
low-cost airlines, budget accommodation) and fierce competition among traditional suppliers as well as the sharing economy suppliers (in the field of accommodation, dining, travel guiding, transport) lead to a price decrease and, in turn, a decline in international tourism receipts per arrival. Secondly, the decreasing average length of overnight stays in line with the trend of travelling more times a year for a shorter period of time has probably had an impact on the growth rate of international tourism receipts per tourist arrival.

Further research could identify the reasons why the growth rate of international tourist arrivals outpaces the growth rate of international tourism receipts per tourist in real terms, how is it related to pricing strategies and what, consequently, are the perceptions and attitudes of residents towards tourists. Additional research could be extended to the overnight stays' growth rate in order to give additional knowledge about how international tourism receipts per overnight stay change.

The limitation of the study is that the growth of international tourism receipts is calculated per arrival as a unit and not per overnight stay, giving somewhat different results, especially for countries with a longer average period of stay. An additional limitation is that only international tourism is analysed. Moreover, it is worth noting that tourism export data use USD, enabling some exchange rate distortions in time series due to exchange rate fluctuations. The analysis is oriented towards demand in the European region where tourism demand is growing slower than in other regions, so the findings cannot be generalised worldwide.

\section{References}

Crouch, G. I. (1994). The study of international tourism demand: A survey of practice. Journal of Travel Research, 32(4), 41-55.

Dogru, T., Sirakaya-Turk, E., \& Crouch, G. I. (2017). Remodeling international tourism demand: Old theory and new evidence. Tourism Management, 60, 47-55.

Garcia-Ferrer, A., \& Queralt, R. A. (1997). A note on forecasting international tourism demand in Spain. International Journal of Forecasting, 13(4), 539-549.

Li, G., Song, H., \& Witt, S., F. (2005). Recent developments in econometric modeling and forecasting. Journal of Travel Research, 44(1), 82-99.

Lim, C. (1997). Review of international tourism demand. Annals of Tourism Research, 24(4), 835-849.

Peng, B., Song, H., \& Crouch, G. I. (2014). A meta-analysis of international demand forecasting and implications for practice. Tourism Management, 45(1), 181-193.

Sheldon, P. J. (1993). Forecasting tourism: Expenditures versus arrivals. Journal of Travel Research, 32(1), 13-20.

Song, H., Dwyer, L., Li, G., \& Cao, Z. (2012). Tourism economics research: A review and assessment. Annals of Tourism Research, 39(3), 1653-1682.

Song, H., Li, G., Witt, S. H., \& Fei, B. (2010). Tourism demand modeling and forecast: How should demand be measured? Tourism Economics, 16(1), 63-81.

World Tourism Organization. (2018). UNWTO Tourism Highlights. 